\title{
Exploration and Analysis of the Reform of Cultivation Model for Animation Talent in Colleges and Universities in the Age of Big Data*
}

\author{
Hui Xie \\ Heihe University \\ Heihe, China
}

\author{
Feng Qi \\ Heihe University \\ Heihe, China
}

\begin{abstract}
Since the 21st century, the development of Internet information technology has been very rapid. New concepts such as big data, "Internet plus" and cloud computing have entered the public view one by one and raised the frenzy of the industrial revolution. The same is true in education industry. The process of animation development in China is very complicated. In recent years, it has lagged far behind the big animation powers such as Japan and the United States. Fundamentally, the root cause for this phenomenon is the shortage of talents. This article analyzes the reform of cultivation model for animation talents in Chinese colleges and universities in the era of big data.
\end{abstract}

Keywords - big data; cultivation mode for animation talent in college and universities; animation talent

\section{INTRODUCTION}

China's animation start is very early. In 1940, Wan brothers made the first cartoon Princess Iron Fan in China while the United States Disney Company launched the first cartoon "Snow White" in 1939. It can be said that China's animation industry is synchronized with the world in its early days. After the founding of New China, China still attached great importance to the animation industry. Some large-scale state-owned animation enterprises headed by the Shanghai Art Film Studio emerged. These enterprises produced excellent animation works like "Little Tadpoles Search for Their Mother" and "Campo Hero Sister", which has aroused great repercussions in the international community. However, due to the economic and cultural background of China, the animation industry has not formed a solid industrial chain. During the Cultural Revolution, animation industry in China was hit so hard that it lagged behind the rest of the world. After the Cultural Revolution, China paid more and more attention to the animation industry. However, under the impact of foreign animation companies, the animation companies in China were severely suppressed, which makes the development of the animation industry in China almost stagnant.

*This paper is the research results of Heihe Institute of Art Research Project research on the influence of "Internet + " development mode on animation industry. "YSY201703

\section{THE SigNIFICANCE OF BIG DATA ON THE ANIMATION INDUSTRY}

In recent years, the word big data often appears in people's vision, so what is the big data? In short, big data refers to the reasonable development and utilization of a large amount of data resulting from the development of information technology to promote the development of the industry. Big data not only refers to the large amount of data, but also refers to the specialized classification and utilization of the helpful data in the mass data, so that data can help companies make profit and achieve the appreciation of the data itself. Enterprises can use big data to analyze customers' preferences, and then provide customers with accurate marketing to increase business returns; they can also use big data to predict the development prospects of enterprises and the market changes in order to make timely transformation of enterprises. Nowadays, the world has entered the era of the Internet, and the relationship between big data and the Internet is very close. So far, there are already many industries using big data to make profit. For example, the ecommerce platform can obtain the customer's shopping preferences by analyzing the customers' visit volume and visit time to a certain product, and then push the product to increase the consumers' desire for consumption. The online loan platform estimate customer repayment ability and borrowing desire by analyzing the customers' consumption information to increase revenue and avoid losses; financial companies predict the ups and downs of the stock by analyzing the public opinion on a listed company. These are typical examples of companies using big data.

Big data has the characteristics of huge amount of data complex types, low value density and high effectiveness. The so-called large amount of data refers that all the behavior of people today will produce data, which led to the amount of big data increase by many orders of magnitude compared with the traditional data volume. Complex types refer that the data in the era of big data, are not only some text data, but also picture data, sound data, video data, location data, and network access data and so on, putting forward higher requirements for multi-type data processing capabilities. Low value density means that only a small part of data in the huge amount of data are useful to the enterprise 
while the rest are of no value. If enterprises want to use big data to drive its development, they must learn to extract useful data from vast amounts of data, which is also one of the most important issues in the current big data field. Effectiveness means that the data in the big data is continuously collected, and people can get the information feedback quickly through the data analysis.

The combination of animation industry and big data ideas will greatly change the face of the animation industry. The using of big data idea in the animation industry has the following major advantages.

\section{A. To Help Animation Companies to Develop Product Direction}

The main profit making way for animation companies is making animation and some cartoon products related to animation. Therefore, for the animation companies, the audience degree of the works is an important factor that determines the profitability of the enterprises. With big data, enterprises can analyze the audience's viewing preferences, gender, age, and education and so on. Then it sums up the acceptance level of people with a certain social attribute for different types of animation, and thus guides the animation creation of enterprises so as to ensure that all the animation works produced by the enterprise have a certain audience.

\section{B. To Forecast the Development Trends of Animation Industry}

Animation industry has very close relationship with social background and national culture. For example, some successful animation works in recent years in China, such as "The Story of Avanti", "Calabash Brothers", "Lotus Lantern", and "Hero Di Qing" are themed with some famous people in history or mythology, and contain some of the ideas of Chinese classical culture. In The Story of Avanti, Avanti uses his own intelligence to sanction the evil rich people and help the poor, which contains the worship of knowledge of ancient China and Confucius' thought of "loving people". In "Calabash Brothers", calabash boys exhausted various ways to save their grandfather. Although the process twists and turns, at last they band together and turn into a colorful lotus that knocks down the lamien and scorpion essence to rescue their grandfather. This cartoon perfectly reflects the traditional filial piety in China and also shows the moral philosophy of "people can move the Mount Taishan when they band together" and "Evil can never prevail over good". "Lotus Lantern" tells the story of Chenxiang saving her mother by cutting the hills, which reflects the filial piety of traditional Chinese culture and the bearing of never bowing to the evil forces. "Hero Di Qing" is about the life of famous general Di Qing in Song Dynasty. It reflects the traditional Chinese virtues through Di Qing's deeds. "Transformers" and "Winnie the Pooh" produced by the United States is more in line with the ideology and culture of the Western world. Traditional animation companies lag behind the times, so they can only choose the theme of the animation according to the current social conditions. However, after using big data, animation companies can analyze people's ideology through big data, and then predict what theme of animation will get wider audience in the future, so that animation companies can walk in front of the times to drive the development of animation industry.

\section{To Optimize the Business Model}

Operation pattern of animation business has great significance in enterprises' profits. In the era of big data, enterprises can use big data to analyze the shortcomings in the operation of the enterprise, continuously optimize the operation mode of the enterprise and improve the operation efficiency of the enterprise.

\section{ThE CURRENT STATUS OF ANIMATION TALENT TRAINING IN CHINA}

Animation major is a major closely related to innovation. To make good animation, animation production staff must have a very strong sense of innovation to dig out new creative materials and use new creative ideas. In addition to the lack of animation production staff, the lack of animation marketing talents and animation operators is also an important factor that restricts the development of China's animation industry. To make a good animation is a very complex job, which needs to take into account all aspects of things and has very high demand for talent. Compared with the developed countries such as the United States and Japan, the animation industry in China started relatively slowly, the mode of animation talent training was relatively backward, and the quality of animation teaching was poor. This results in that the number of animation talents in China is far less than the market demand. The main reasons for this phenomenon are the followings: poor faculty, backward education philosophy, single training source, insufficient motivation.

At present, schools engaged in the cultivation of cartoon talents in China includes social training institutes, vocational colleges, specialized art colleges and universities, and the arts major of ordinary colleges and universities. All these assume all the responsibility of outputting animation talents. The social training institutions are mainly employmentoriented, so students who study in the training institutions mainly develop their animation skills. They have very strong employability but their innovative ability is poor. They often can adapt quickly to work after they enter the job, but they lack follow-up development power and the salary rises slower. The same is true to vocational colleges. Students majoring in art major in art colleges and universities have very strong knowledge base. After graduation, they cannot quickly adapt to the job, and often need some retraining for a while. However, these students have very strong ability to innovate compared with students of social training institutions and vocational college, so their future development prospects are very good. Many animation companies in China blindly pursue profit without attaching importance to the long-term development of enterprises, which leads that graduates from ordinary colleges and art schools in the enterprise be pushed aside by companies and colleagues. Companies did not give them sufficient time to adapt, resulting in the high rate of changing career of animation college graduates, so many students quickly 
change the job over a very short period of time because they cannot adapt to the job demand. This exacerbates the situation of lack of animation talent.

Since the animation industry interrupted for some time in the developing process, the talents of animation industry in China are not enough and the really good teachers are poor with low teaching quality. Moreover, the current companies put interests in the first place while put less emphasis on the original. They often whatever make money. In the long run, the original ability of animation practitioners becomes lower and lower, leading them to be unable to produce good original animation. There are also many companies addicted to using animation brands. Animation industry in Changsha, for example, in the early stages of the development of animation in China, produced a classic "3000 questions of blue cat naughty", "Rainbow Cat and Blue Rabbit Seven Chivalrous Biography". However, after these works made a hit, they did not apply the production experience to the creation of other new works. Instead, they continued to produce some similar animation works with the ideas that they would make money as long as they continue to make the series, which is indeed a good way to make money in a short period of time, but over time the audience will have aesthetic fatigue. At this moment, the enterprise begins to launch a new animation brand, but the innovation capability of the staff has been greatly different from that in the previous. The quality of animation works cannot be guaranteed. Schools weaken with the cooperation of enterprises, so all aspects of animation talent training are independent of each other, which is also a very important factor that impacts the animation talent training in China. Animation talent cultivation is a multi-faceted process. The school can only teach students some basic theoretical knowledge but cannot teach them the application capacity. However, they can exercise their practical abilities in the enterprises. Therefore, the cooperation between schools and enterprises should be strengthened so as to increase students' practice opportunities, which will enhance students' comprehensive ability and employment competitiveness of university graduates to reduce the loss of animation talents.

\section{REFORM OF ANimATION TALENT TRAINING OF COLLEGES UNDER THE BIG DATA}

\section{A. To Promote Industrial Innovation through Big Data}

To make innovation, the most important thing for animation industry is to dig out new creative materials and change the creative tone of animation industry. Big data is a new tool for animation companies to explore innovative materials. By using big data technology animation companies can quickly identify those attracting more attention, such as behavior and culture, etc., and then select something as animation materials from these attracting people' attention, so that they can make sure animation works can get support from people. In addition, the development of cloud computing technology closely related to big data is also very rapid. Some commercial giants such as Alibaba have started to develop their own cloud computing enterprises. In the process of animation production, the use of cloud computing technology can significantly improve the speed and quality of processing as well as the animation quality of anime companies. Moreover, enterprises can use the cloud computing function only by paying a certain rent without purchasing the whole device, which makes some less funded enterprises also be able to compete with large enterprises and improve the living environment of small animation companies.

\section{B. To Use Big Data to Find Market Demand}

The development of computer technology has also promoted the development of animation production technology, and the new animation production technology has sprung up like mushrooms. The market demand is constantly changing, so companies should have a correct understanding of market demand to gain a foothold in the market. The traditional animation industry develops mainly driven by the leading enterprises. The animation enterprises' understanding of the demand of the social market is not clear enough, so the teaching of colleges and universities can only adopt fuzzy teaching to foster students' theoretical basic knowledge. After using big data, the school can quickly find out the market demand, and then promptly change the teaching guidelines and teaching strategies to enable students to have strong employment competitiveness after graduation to find a job easily, thus reducing the loss of animation talent.

\section{To Strengthen Cooperation between School and Enterprise}

The development of animation industry has high regionality and expansibility, and the development orientations of animation in different regions are also different. Therefore, in the teaching process, colleges and universities should also consider such regionality and expansibility. Teachers in schools should reasonably integrate and plan the teaching content to develop a set of teaching system in line with the local actual situation. In addition, schools should also strengthen their cooperation with local enterprises. Schools pay attention to the cultivation of basic theoretical knowledge while enterprises focus on the practical ability. If the two emphasize on either side, it will result in problems in the students' career development. Only by increasing students' practical learning time can we let students to really see how animation companies work, and how employees in animation companies work, so they can find the focus of learning in their studying process. Moreover, enterprises tend to be more sensitive to market demand. By strengthening schoolenterprise cooperation, schools can find outdated places in their own teaching system and then make timely corrections. This will put the teaching process on the shoulders of big data, which make them see farther. This also contributes to the long-term development of students and improves the teaching ability of the school.

\section{CONCLUSION}

The impact of big data on the animation industry is huge, and animation talents in colleges and universities are also the source of vitality for the development of the animation 
industry. Only by cultivating students with strong comprehensive ability and innovative ability can the original ability and production level of animation industry in China be enhanced. To cultivate such students, we must grasp the market demand and strengthen the cooperation with enterprises. This article starts with the impact of big data on the animation industry, analyzes the shortcomings of the training of animation talent in colleges and universities in China, and finally analyzes the reform of the training pattern of animation talents in colleges and universities based on the theory of big data, hoping to bring some enlightenment to the teaching of colleges and universities.

\section{REFERENCES}

[1] Hao Shuixia, Guo Yunxia.New Exploration of Training Modes of Information and Computational Science major Under the Age of Big Data. Journal of Jiangsu Normal University(Natural Science Edition), 2016, 34(2):72-75.

[2] Li Mingming, Wei Fengyu, Zeng Qi, et al. Study on the training mode of logistics management talents in higher vocational college under the era of big data. Logistics engineering and management, 2015(3):248-249.

[3] Xi Yanli, Wang Shuran. Study on the training mode of applied talents of preventive medicine under the era of big data. China Educational Technology \& Equipment, 2015(6):55-56.

[4] Liu Yiying. Research on the Training of Data Talents in Colleges and Universities in the Age of Big Data. Inheritance \& Innovation, 2015(12):112-113.

[5] Li Mei. development trend and talent training mode of art education in colleges and universities during the big data era. Art Education Research, 2016(9):94-96. 